\title{
Article \\ Clinical and Tumor Characteristics of Patients with High Serum Levels of Growth Differentiation Factor 15 in Advanced Pancreatic Cancer
}

\author{
Hidetaka Suzuki 1,2,3@ , Shuichi Mitsunaga ${ }^{1,4, *}$, Masafumi Ikeda ${ }^{4}\left({ }^{\circ}\right.$, Takao Aoyama ${ }^{2}$, Kazumi Yoshizawa ${ }^{5}$, \\ Hiroki Yoshimatsu ${ }^{6}$, Norisuke Kawai ${ }^{6}$, Mari Masuda ${ }^{7}$, , Tomofumi Miura ${ }^{1}$ and Atsushi Ochiai ${ }^{1}$ \\ 1 Division of Biomarker Discovery, Exploratory Oncology Research \& Clinical Trial Center, \\ National Cancer Center, Kashiwa 277-8577, Japan; hidesuzu@east.ncc.go.jp (H.S.); \\ tomiura@east.ncc.go.jp (T.M.); aochiai@east.ncc.go.jp (A.O.) \\ 2 Laboratory of Pharmacotherapeutics, Faculty of Pharmaceutical Science, Tokyo University of Science, \\ Tokyo 278-8510, Japan; t-aoyama@rs.noda.tus.ac.jp \\ 3 Department of Pharmacy, National Cancer Center Hospital East, Kashiwa 277-8577, Japan \\ 4 Department of Hepatobiliary and Pancreatic Oncology, National Cancer Center Hospital East, \\ Kashiwa 277-8577, Japan; masikeda@east.ncc.go.jp \\ 5 Laboratory of Pharmacology and Therapeutics, Faculty of Pharmaceutical Science, Tokyo University of Science, \\ Tokyo 278-8510, Japan; yoshizawa-ph@rs.tus.ac.jp \\ 6 Pfizer R\&D Japan G.K., Tokyo 151-8589, Japan; Hiroki.Yoshimatsu@pfizer.com (H.Y.); \\ Norisuke.Kawai@pfizer.com (N.K.) \\ check for \\ updates \\ 7 Department of Proteomics, National Cancer Center Research Institute, Tokyo 104-0045, Japan; \\ mamasuda@ncc.go.jp \\ * Correspondence: smitsuna@east.ncc.go.jp; Tel.: +81-4-7133-1111; Fax: +81-4-7133-6865
}

Citation: Suzuki, H.; Mitsunaga, S.; Ikeda, M.; Aoyama, T.; Yoshizawa, K.; Yoshimatsu, H.; Kawai, N.; Masuda, M.; Miura, T.; Ochiai, A. Clinical and Tumor Characteristics of Patients with High Serum Levels of Growth Differentiation Factor 15 in Advanced Pancreatic Cancer. Cancers 2021, 13, 4842. https://doi.org/10.3390/ cancers13194842

Academic Editor: Atsushi Umemura

Received: 10 September 2021

Accepted: 26 September 2021

Published: 28 September 2021

Publisher's Note: MDPI stays neutral with regard to jurisdictional claims in published maps and institutional affiliations.

Copyright: (c) 2021 by the authors. Licensee MDPI, Basel, Switzerland. This article is an open access article distributed under the terms and conditions of the Creative Commons Attribution (CC BY) license (https:/ / creativecommons.org/licenses/by/ $4.0 /)$.
Simple Summary: Growth differentiation factor 15 (GDF-15) is a stress responsive cytokine that mediates food intake, energy consumption, and body weight. We aimed to evaluate whether circulating GDF-15 level could be associated with cachexia symptoms, which include loss of skeletal muscle mass, systemic inflammatory reaction, poor performance status, anorexia, shortened survival time and biological tumor activity in advanced pancreatic cancer (APC). The cut-off for serum GDF-15 was $3356.6 \mathrm{pg} / \mathrm{mL}$, as the mean plus two standard deviations in patients with benign pancreatic disease. APC patients with high serum GDF-15 showed worsened performance, anorexia and elevations of inflammatory and tumor burden, signatures of cachexia, and activation of Akt and JNK in tumor GDF-15-producing pathways. This study identified tumor-driven GDF-15 as a potential cause of cachexia symptoms in APC.

Abstract: We aimed to evaluate the association of circulating growth differentiation factor 15 (GDF-15) with cachexia symptoms and the biological activity of advanced pancreatic cancer (APC). Treatmentnaïve patients with liver metastasis of APC or with benign pancreatic disease were retrospectively analyzed. Clinical data, blood samples, and biopsy specimens of liver metastasis were collected prior to anti-cancer treatment. Serum GDF-15 levels and multiple protein expressions in lysates extracted from liver metastasis were measured by enzyme-linked immuno-sorbent assay and reverse-phase protein array, respectively. The cut-off for serum GDF-15 was determined as $3356.6 \mathrm{pg} / \mathrm{mL}$, the mean plus two standard deviations for benign pancreatic disease. The high-GDF-15 group was characterized as showing low Karnofsky performance status (KPS) $(p=0.037)$, poor Eastern Cooperative Oncology Group performance status (ECOG-PS) $(p=0.049)$, severe appetite loss $(p=0.011)$, and high serum levels of carbohydrate antigen 19-9 $(p=0.019)$ and C-reactive protein $(p=0.009)$. Tumors of the high-GDF-15 group expressed high levels of phosphorylated (p)JNK $(p=0.007)$ and pAkt $(p=0.040)$. APC patients with high serum GDF-15 showed signatures of cachexia and activation of the signaling pathways involving Akt and JNK in the tumor. This study indicated circulating GDF-15 could be associated with cachectic symptoms in APC. 
Keywords: growth differentiation factor 15; pancreatic cancer; anorexia; cancer cachexia

\section{Introduction}

As a member of the transforming growth factor (TGF)- $\beta$ subfamily, growth differentiation factor 15 (GDF-15) is a stress-responsive cytokine associated with various diseases such as cancers [1-5], cardiovascular disorders [6], mitochondrial disorders [7], hyperthyroidism [8], obesity and type 2 diabetes [9]. GDF-15 mediates food intake, energy consumption, and body weight $[10,11]$. Circulating GDF-15 binds to the GDNF family receptor a-like (GRFAL)/RET receptor complex in the brain stem, triggering receptor phosphorylation and downstream intracellular signaling [10]. The signaling of GFRAL antagonism and agonism, respectively, increase and decrease food intake [10]. High circulating levels of GDF-15 in cancer patients have been associated with chemoresistance, anorexia, emesis and weight loss [12-14], all of which are symptoms of cachexia [15]. Cachexia is defined as a multiple metabolic disorder characterized by an ongoing loss of skeletal muscle mass [16]. This pathology is frequently seen in patients with advanced pancreatic cancer (APC) [17], who show systemic inflammation and worsened performance status (PS) [18-20]. One possibility is that elevated levels of circulating GDF-15 are associated with cachectic symptoms, including loss of skeletal muscle mass, systemic inflammatory reaction, poor PS, anorexia, and shortened survival time.

Expression of GDF-15 is maintained at low levels in most tissues [21] and is increased by p53 activation due to various cellular stressors, such as inflammation, oxidative stress, hypoxia, and oncogene activation [22]. Serum GDF-15 levels in the patients with chronic pancreatitis were higher, $2248 \mathrm{pg} / \mathrm{mL}$ in mean [1] compared to healthy subjects (416.8 pg/mL [23], 546 [24], 639 [25] in mean). Pancreatic disease compressing the pancreatic duct is considered to increase the GDF-15 level, and thus can result from benign pancreatic diseases including chronic pancreatitis, intraductal papillary mucinous tumor, and serous cystic tumor. The cut-off level to characterize a high serum level of GDF-15 in APC thus should discriminate cancer-related upregulation of GDF-15 from the effects of benign pancreatic disease. We therefore planned to determine the upper limit of serum GDF-15 levels in benign pancreatic diseases, in order to set an appropriate cut-off to discriminate low and high serum GDF-15 groups for APC.

Solid stress increased GDF-15 expression by transcriptionally regulating GDF-15 expression through activation of the Akt pathway in pancreatic cancer cells [26]. Stress responses involving the Akt pathway can become dominant in cases with pancreatic cancer complicated by high levels of circulating GDF-15, providing biological validation for a cut-off for serum GDF-15 in pancreatic cancer. The clinical and tumoral characteristics of APC patients with high serum GDF-15 levels are expected to provide useful information for elucidating the causes of clinical symptoms triggered by stress responses in the tumor microenvironment.

We undertook the present study to investigate the following in APC patients: (A) an appropriate cut-off value for serum GDF-15 levels; (B) the relationship between serum GDF-15 levels and clinical data; and (C) tumor characteristics associated with high serum levels of GDF-15.

\section{Materials and Methods}

\subsection{Ethics}

This study was approved by the ethics review committee of National Cancer Center Hospital East (approval no. 2020-373).

\subsection{Patients}

Treatment-naïve patients with liver metastasis from pathologically proven APC or with benign pancreatic disease were eligible to participate in this study. Subjects were 
registered between 5 August 2011 and 7 January 2015 at the National Cancer Center Hospital East. Benign pancreatic diseases comprised chronic pancreatitis, intraductal papillary mucinous tumor, non-invasive intraductal papillary mucinous carcinoma, and serous cystic tumor. Written informed consent was obtained from all subjects before enrollment.

\subsection{Definition of Cancer Cachexia and Sarcopenia}

In this study, we defined cancer cachexia as either weight loss $>5 \%$ or weight loss $>2 \%$ with a body mass index $(\mathrm{BMI})<20 \mathrm{~kg} / \mathrm{m}^{2}$ [16]. Base cachexia was defined as weight loss within 6 months before starting chemotherapy. Sarcopenia was diagnosed using the Japan Society of Hepatology criteria [27] as low handgrip strength $(<26 \mathrm{~kg}$ for males; $<18 \mathrm{~kg}$ for females) and low muscle mass ( $<42 \mathrm{~cm}^{2} / \mathrm{m}^{2}$ for males; $<38 \mathrm{~cm}^{2} / \mathrm{m}^{2}$ for females). Muscle mass was evaluated as the skeletal muscle index (SMI) at the level of the third lumbar vertebra (L3) on computed tomography.

\subsection{Data Collection}

Body weight, Karnofsky performance status (KPS), Eastern Cooperative Oncology Group performance status (ECOG-PS), laboratory tests, severity of symptoms (the Japanese version of the MD Anderson Symptom Inventory; MDASI-J) [28] and a blood sample were collected before anti-cancer treatment. MDASI-J is a 13-item symptom scale (pain, fatigue, nausea, disturbed sleep, distress, shortness of breath, memory, lack of appetite, drowsiness, dry mouth, sadness, vomiting, and numbness or tingling) rated numerically from 0 ("not present") to 10 ("as bad as you can imagine") based on symptoms present over the preceding $24 \mathrm{~h}$. Severe appetite loss was defined as MDASI-J $\geq 2$, as per our previous study [29]. The cut-off for serum levels of C-reactive protein (CRP) was determined as $2.0 \mathrm{mg} / \mathrm{dL}$ in accordance with our previous study [20]. The cut-off for carbohydrate antigen (CA)19-9 was defined as above median serum CA19-9 level, which was $4150 \mathrm{U} / \mathrm{mL}$ in our study.

\subsection{Enzyme-Linked Immuno-Sorbent Assay (ELISA)}

Blood samples were collected in a serum-separating tube on the morning after overnight fasting and completely clotted for 30-60 $\mathrm{min}$ at room temperature. After centrifugation at $1500 \mathrm{~g}, 25^{\circ} \mathrm{C}$ for $15 \mathrm{~min}$, serum samples were separated and frozen at $-80^{\circ} \mathrm{C}$ until analysis. Serum GDF-15 levels were quantitatively determined in duplicate using an ELISA kit in accordance with the protocol from the manufacturer (R\&D Systems, Minneapolis, MN, USA).

\subsection{Protein Expression Analysis}

Tissue cores were obtained from liver metastases of APC with endoscopic ultrasonographyguided fine-needle aspiration biopsy (FNAB) [30]. Immediately after the procedure, a tissue core specimen was homogenized with tissue-Lyser II (QIAGEN, Hilden, Germany) in the lysis buffer of a NucleoSpin TriPrep kit (Macherey-Nagel, GmbH \& Co., KG, Düren, Germany), and was filtered with the NucleoSpin TriPrep kit. After protein purification with a Pierce ${ }^{\mathrm{TM}}$ SDS-PAGE Sample Prep Kit (Thermo Fisher Scientific, Waltham, MA, USA), the lysate was snap-frozen and stored at $-80^{\circ} \mathrm{C}$ until needed. Reverse-phase protein array (RPPA) analysis of lysates was performed at the functional proteomic RPPA core facility of the MD Anderson Cancer Center. Briefly, tissue lysates were serially diluted two-fold for five dilutions (Undiluted, 1:2, 1:4, 1:8, and 1:16) and arrayed onto nitrocellulose-coated slides [31,32]. RPPA slides immunostained with 435 primary antibodies were scanned with a TissueScope scanner (HURON Digital Pathology, St. Jacobs, ON, Canada), and the signal intensity of each spot on the arrays was quantified using Array-pro Analyzer 6.3 software (Media Cybernetics, Silver Spring, MD, USA). The relative protein levels of analytes in each sample were then determined using the SuperCurve 1.5.0 R package via SuperCurveGUI 2.1.1. [33]. RPPA analysis was performed in the patients whose protein samples could be extracted, purified, and detected as a reproducible band of $\beta$-actin in western blotting. 


\subsection{Statistical Analyses}

Continuous data were compared using the Mann-Whitney $U$ test. Associations between serum GDF-15 levels and each categorical variable were examined using a chisquare test or Fisher's exact test. Fisher's exact test and chi-square test were used for analysis of $2 \times 2$ contingency tables and more than $2 \times 2$ consistency tables, respectively. Overall survival (OS) was calculated from the starting date of first-line chemotherapy or BSC. Progression-free survival (PFS) was calculated only in patients with chemotherapy from the starting date of first-line chemotherapy. Survival curves were drawn using the Kaplan-Meier method. OS and PFS were compared using the log-rank test between lowand high-GDF-15 groups of APC patients with liver metastasis. For all statistical tests, values of $p<0.05$ were considered statistically significant. Median survival times were calculated with $95 \% \mathrm{CIs}$, as determined using the Brookmeyer and Crowley method. Data analyses were performed using JMP ${ }^{\circledR}$ version 11 software (SAS Institute, Cary, NC, USA).

\section{Results}

\subsection{Cut-Off Value for Serum GDF-15 Levels}

The CONSORT diagram for this study is shown in Figure 1. A total of 120 patients were included and analyzed in this study, of whom 99 patients had liver metastasis of APC (38 women, 61 men; median age, 66.2 years; range, 39-85 years). The remaining 21 patients had benign pancreatic disease (10 women, 11 men; median age, 69.0 years; range, 50-81 years), including chronic pancreatitis $(n=4,19.1 \%)$, intraductal papillary mucinous tumor $(n=15,71.4 \%)$ and serous cystic tumor $(n=2,9.5 \%)$.

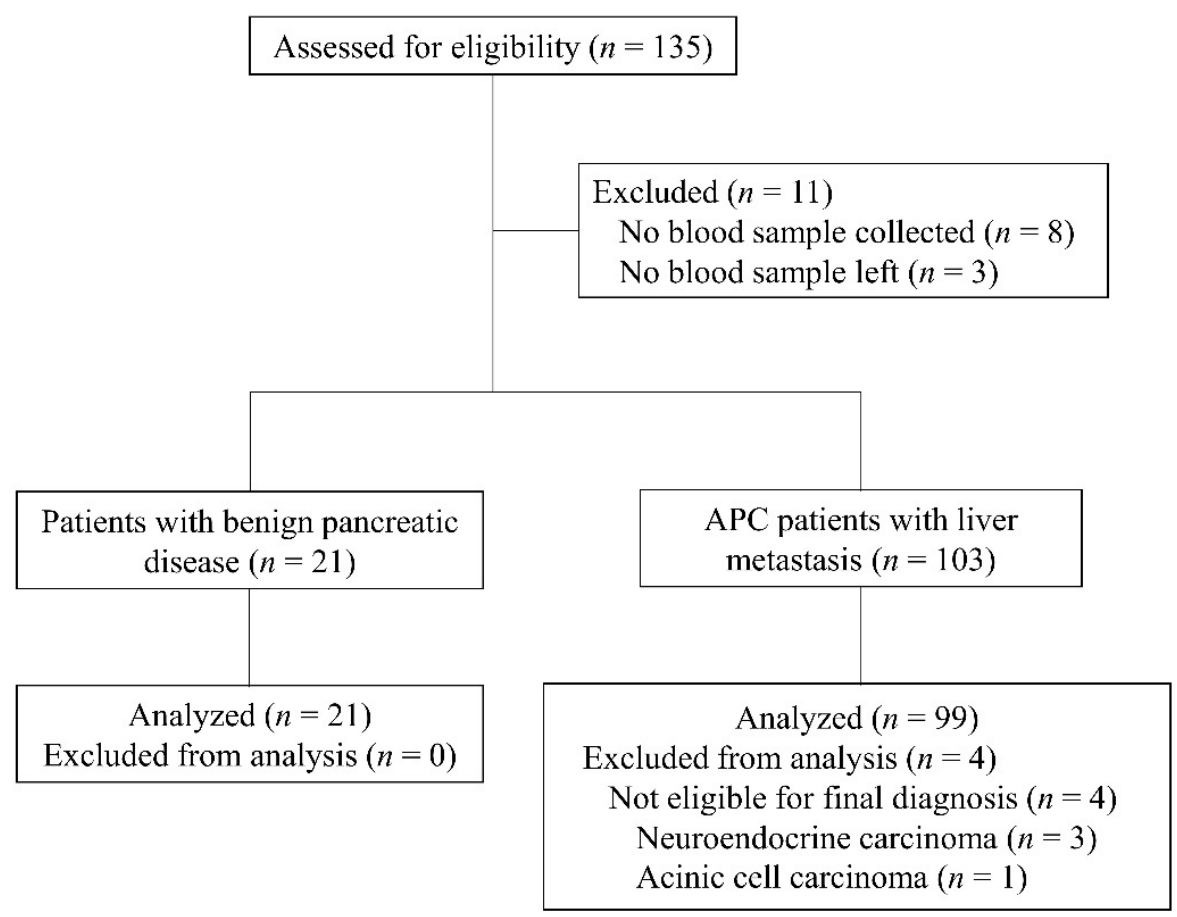

Figure 1. Consort diagram. APC, advanced pancreatic cancer.

Mean ( \pm standard deviation [SD]) serum GDF-15 levels were significantly higher in the 99 patients with liver metastasis of APC $(2990.2 \pm 1967.0 \mathrm{pg} / \mathrm{mL})$ than in the 21 patients with benign disease $(1177.0 \pm 1089.8 \mathrm{pg} / \mathrm{mL} ; p<0.001)$ (Figure 2$)$. The cut-off value was determined as $3356.6 \mathrm{pg} / \mathrm{mL}$, representing the mean plus twice the SD of the serum GDF15 level in patients with benign disease, (Figure 2). As a result, $34.3 \%(n=34)$ of the 99 APC patients were classified as the high-GDF-15 group. Mean serum GDF-15 levels were $5257.0 \pm 1649.9 \mathrm{pg} / \mathrm{mL}$ in the high-GDF-15 group and $1804.5 \pm 602.5 \mathrm{pg} / \mathrm{mL}$ in the low-GDF-15 group. 


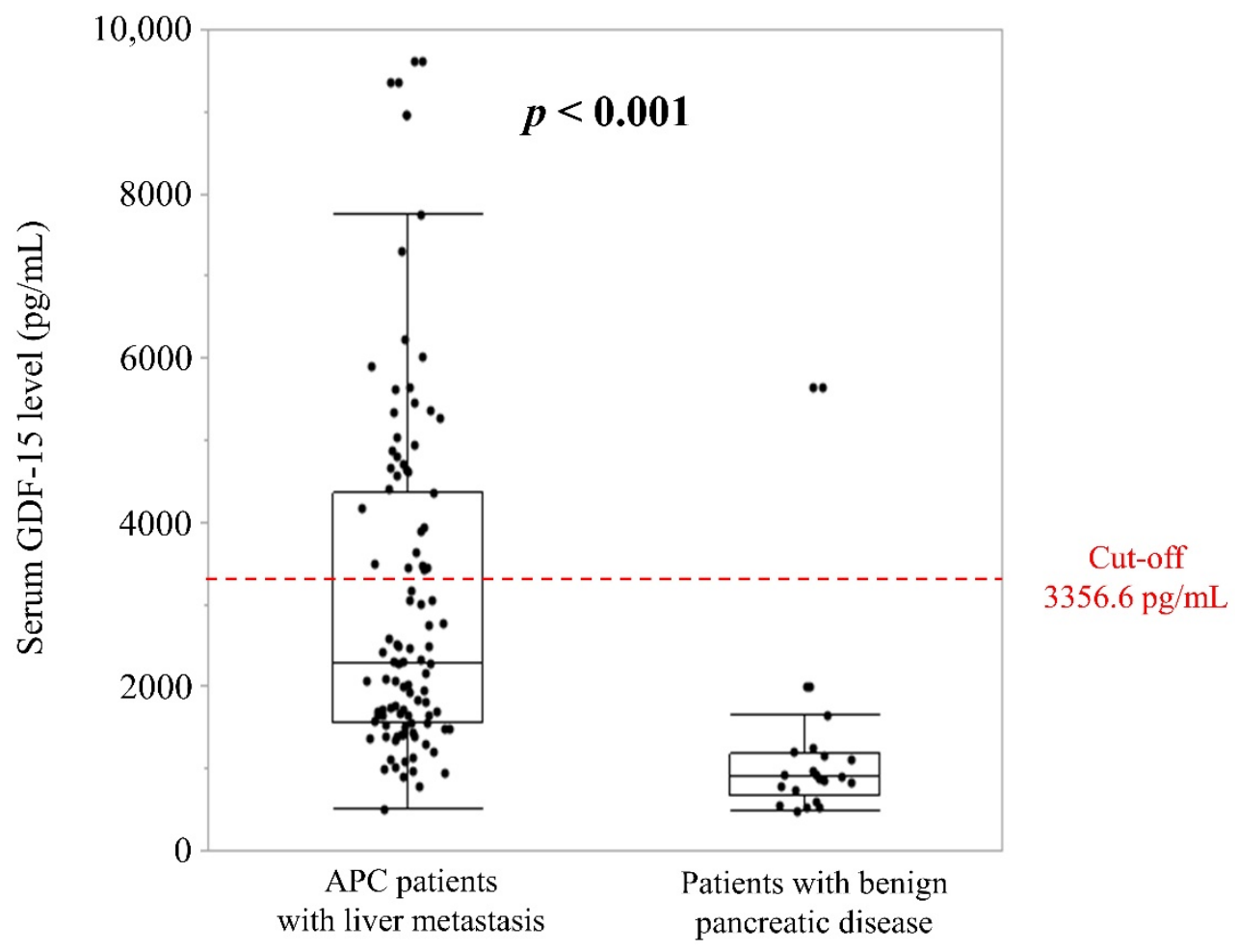

Figure 2. Serum GDF-15 levels in APC patients with liver metastasis and benign pancreatic diseases. The red dotted line represents the cut-off for serum GDF-15 levels, determined as the mean plus twice the standard deviation of GDF-15 in patients with benign pancreatic disease, equal to $3356.6 \mathrm{pg} / \mathrm{mL}$.

\subsection{Baseline Clinical Characteristics}

Among the 99 APC patients, 87 patients (87.9\%) received first-line chemotherapy, comprising gemcitabine + nab-paclitaxel $(n=3,3.0 \%$ ); FOLFIRINOX (fluorouracil, leucovorin, irinotecan, and oxaliplatin) $(n=14,14.1 \%)$; gemcitabine $(n=26,26.3 \%)$; gemcitabine + erlotinib ( $n=32,32.3 \%)$; and others $(n=12,12.1 \%)$. The remaining 12 patients $(22.1 \%)$ received the best supportive care (BSC). The characteristics of patients with high serum GDF-15 levels included low KPS ( $p=0.037)$, poor ECOG-PS ( $p=0.049)$, high serum CA19-9 levels $(p=0.019)$, high serum CRP levels $(p=0.009)$, and severe appetite loss $(p=0.011)$ (Table 1). The proportion of patients receiving chemotherapy was significantly lower in the high-GDF-15 group (76.5\%) than in the low-GDF-15 group $(93.9 \%, p=0.020)$ (Table 1$)$. No significant differences in other baseline clinical data were apparent between high- and low-serum GDF-15 levels, including proportion of chemotherapy regimen.

Actual mean serum GDF-15 levels were high in groups with severe appetite loss $(n=48)$, high CRP $(n=43), \mathrm{KPS}<90(n=42)$, and CA19-9 $>4150 \mathrm{U} / \mathrm{mL}(n=49)$ as compared to groups with non-severe appetite loss $(n=43 ; 3407.1 \mathrm{pg} / \mathrm{mL}$ vs. $2285.9 \mathrm{pg} / \mathrm{mL} ; p=0.003$; Figure $3 \mathrm{~A})$, low serum CRP $(n=56 ; 3581.0 \mathrm{pg} / \mathrm{mL}$ vs. $2535.5 \mathrm{pg} / \mathrm{mL} ; p=0.013$; Figure $3 \mathrm{~B}), \mathrm{KPS} \geq 90$ $(n=49 ; 3274.32 \mathrm{pg} / \mathrm{mL}$ vs. $2367.3 \mathrm{pg} / \mathrm{mL} ; p=0.001$; Figure 3 C), and CA19-9 $\leq 4150 \mathrm{U} / \mathrm{mL}$ $(n=50 ; 3348.3 \mathrm{pg} / \mathrm{mL}$ vs. $2639.2 \mathrm{pg} / \mathrm{mL} ; p=0.027$; Figure 3D), respectively. 
Table 1. Univariate analysis of baseline clinical characteristics to identify factors related to serum GDF-15 levels in patients with metastatic APC.

\begin{tabular}{|c|c|c|c|c|}
\hline \multirow{2}{*}{ Variables } & & \multicolumn{2}{|c|}{ Serum GDF-15 Levels } & \multirow{2}{*}{$p$-Value } \\
\hline & & Low & High & \\
\hline \multirow[t]{2}{*}{ Sex } & Male & $42(64.6 \%)$ & $19(55.9 \%)$ & \multirow[t]{2}{*}{0.514} \\
\hline & Female & $23(35.4 \%)$ & $15(44.1 \%)$ & \\
\hline Age (years) & Median (range) & $67.0(39-85)$ & $65.9(50-85)$ & 0.665 \\
\hline KPS & Median (range) & $90(60-100)$ & $80(60-100)$ & 0.037 \\
\hline \multirow[t]{3}{*}{ ECOG-PS } & 0 & $36(56.3 \%)$ & $9(31.0 \%)$ & \multirow[t]{3}{*}{0.049} \\
\hline & 1 & $25(39.1 \%)$ & $16(55.2 \%)$ & \\
\hline & 2 & $3(4.7 \%)$ & $4(13.8 \%)$ & \\
\hline Chemotherapy & Yes & $61(93.9 \%)$ & $26(76.5 \%)$ & 0.020 \\
\hline \multirow[t]{5}{*}{ Regimen } & GEM + nab-PTX & $2(3.3 \%)$ & $1(3.8 \%)$ & \multirow[t]{5}{*}{0.738} \\
\hline & Modified FOLFIRINOX & $10(16.4 \%)$ & $4(15.4 \%)$ & \\
\hline & GEM monotherapy & $16(26.2 \%)$ & $10(38.5 \%)$ & \\
\hline & GEM + Erlotinib & $23(37.7 \%)$ & $9(34.6 \%)$ & \\
\hline & others & $10(16.4 \%)$ & $2(7.7 \%)$ & \\
\hline CEA (ng/mL) & Median (range) & $14.8(0.9-363.4)$ & $26.4(1.3-1441.0)$ & 0.247 \\
\hline CA19-9 (U/mL) & Median (range) & $\begin{array}{c}2995.0 \\
(0.1-330,600.0) \\
\end{array}$ & $\begin{array}{c}10771.5 \\
(0.5-343,352.0)\end{array}$ & 0.019 \\
\hline Ascites & Present & $34(52.3 \%)$ & $14(41.2 \%)$ & 0.397 \\
\hline Peritoneal metastasis & Present & $28(43.1 \%)$ & $19(55.9 \%)$ & 0.290 \\
\hline $\begin{array}{l}\text { Biliary Drainage before starting } \\
\text { chemotherapy }\end{array}$ & Present & $8(12.3 \%)$ & $5(14.7 \%)$ & 0.760 \\
\hline Lung metastasis & Present & $14(21.5 \%)$ & $6(17.7 \%)$ & 0.794 \\
\hline Distant lymph node metastasis & Present & $4(6.1 \%)$ & $5(14.7 \%)$ & 0.268 \\
\hline Serum CRP levels (mg/dL) & Median (range) & $1.20(0.03-18.58)$ & $3.22(0.06-21.72)$ & 0.009 \\
\hline \multirow[t]{2}{*}{ Cachexia } & Cachexia & $37(56.9 \%)$ & $17(50.0 \%)$ & \multirow[t]{2}{*}{0.531} \\
\hline & Non-cachexia & $28(43.1 \%)$ & $17(50.0 \%)$ & \\
\hline \multirow[t]{2}{*}{ Sarcopenia } & Sarcopenia & $19(33.9 \%)$ & $10(52.6 \%)$ & \multirow[t]{2}{*}{0.179} \\
\hline & Non-sarcopenia & $37(66.1 \%)$ & $9(47.4 \%)$ & \\
\hline $\mathrm{SMI}\left(\mathrm{kg} / \mathrm{m}^{2}\right)$ & Median (range) & $44.26(27.40-52.10)$ & $40.14(28.28-52.88)$ & 0.203 \\
\hline MDASI-J appetite loss & Median (range) & $1(0-10)$ & $4(0-10)$ & 0.011 \\
\hline Body weight loss (\%) & Median (range) & $5.74(-17.42-22.81)$ & $5.03(-1.72-30.00)$ & 0.690 \\
\hline
\end{tabular}

Fisher's exact test or the chi-square test were used for comparisons of categorical variables between the low-GDF-15 group (serum GDF-15 level < 3356.6 pg/mL) and the high-GDF-15 group (serum GDF-15 level $\geq 3356.6 \mathrm{pg} / \mathrm{mL}$ ). KPS, Karnofsky performance status; ECOG-PS, Eastern Cooperative Oncology Group performance status; GEM, gemcitabine; nab-PTX, nab-paclitaxlel; CEA, carcinoembryonic antigen; CA19-9, carbohydrate antigen 19-9; CRP, C-reactive protein; SMI, skeletal muscle mass index; MDASI-J, Japanese version of the MD Anderson Symptom Inventory. 

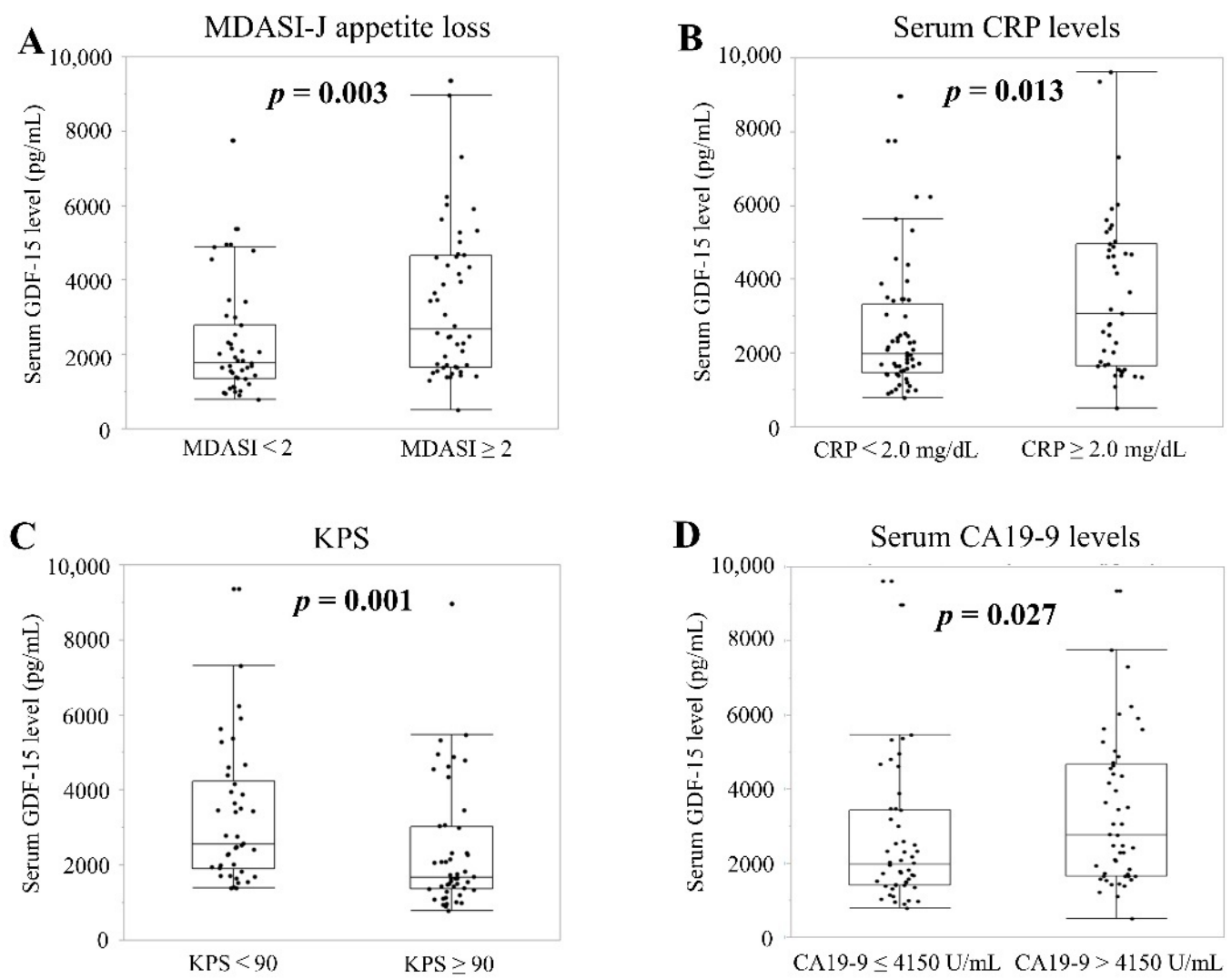

Figure 3. Relationship between serum GDF-15 levels and clinical parameters related to cachexia and disease progression in patients with liver metastasis of APC. Parameters include (A) appetite loss; (B) CRP; (C) KPS; and (D) CA19-9. MDASI-J, Japanese version of the MD Anderson Symptom Inventory; CRP, C-reactive protein; KPS, Karnofsky performance status; CA19-9, carbohydrate antigen 19-9.

\subsection{Survival}

Median OS was 4.10 months (95\% confidence interval [95\%CI], 3.33-5.87 months) for all 99 patients with APC, 2.70 months ( $n=34$; 95\%CI, 1.37-5.83 months) for high-GDF15 patients and 5.70 months $(n=65 ; 95 \% C I, 3.63-7.60$ months $)$ for low-GDF-15 patients $(p=0.113)$.

In the 87 patients who received chemotherapy, the median OS was 5.57 months $(95 \% \mathrm{CI}$, 3.63-6.53 months). Median OS was 3.33 months ( $n=26$; 95\%CI, $1.73-5.87$ months) for high-GDF-15 patients and 5.87 months $(n=61 ; 95 \% C I, 3.70-7.97$ months) for low-GDF-15 patients. No significant differences in OS were evident between high- and low-GDF-15 patients $(p=0.254)$ (Figure 4A).

Median PFS was 2.20 months (95\%CI, 1.83-2.87 months) for the 87 patients with chemotherapy, 1.58 months $(n=26$; 95\%CI, 0.97-2.73 months) for high-GDF-15 patients, and 2.60 months ( $n=61 ; 95 \%$ CI, 1.90-3.20 months) for low GDF-15 patients $(p=0.546)$. No significant differences in PFS were apparent between high- and low-GDF-15 patients (Figure 4B). 

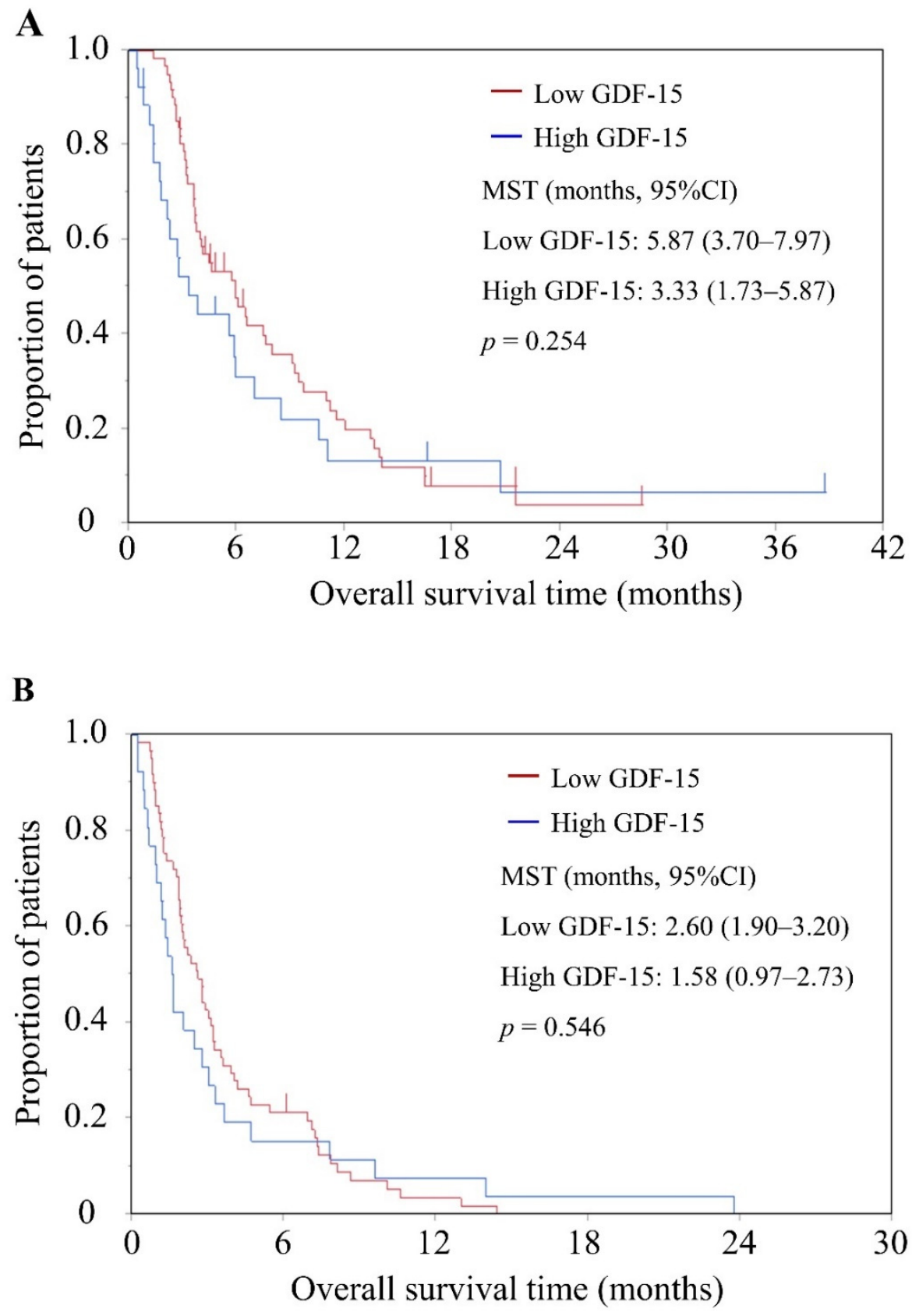

Figure 4. Overall survival (OS) and progression-free survival (PFS) according to high or low serum GDF-15 levels in patients with liver metastasis of APC. Kaplan-Meier plots of (A) OS and (B) PFS for patients receiving chemotherapy. MST, median survival time.

\subsection{Tumor Characteristics}

RPPA analysis was performed in $38.2 \%(n=13)$ of high-GDF-15 patients $(n=34)$ and $41.5 \%(n=27)$ of low-GDF-15 patients $(n=65)$. In this study, 435 proteins and phosphoproteins were analyzed in the lysates of FNAB tissue cores from liver metastases of APC patients. Significant differences between the low- and high-GDF-15 groups were found for 12 proteins (Table S1), including phospho-(p)JNK (threonine183_tyrosine185) and pAkt (threonine 308), both of which were significantly higher in the high-GDF-15 group than in the low-GDF-15 group (pJNK: 0.046 vs. -0.094 in mean, $p=0.007$, Figure 5A; pAkt: 0.123 vs. $-0.020, p=0.040$, Figure $5 \mathrm{~B}$ ).

The 40 APC patients who underwent tumor analysis by RPPA were separated into two groups according to median expression levels (pJNK: -0.0256 and pAkt: 0.0036 ). 
Mean serum GDF-15 levels were significantly higher in the groups with pJNK expression level $\geq-0.0256(n=19)$ and pAkt expression level $\geq 0.0036(n=21)$ than in the groups with pJNK expression level $<-0.0256(n=21 ; 3522.6 \mathrm{pg} / \mathrm{mL}$ vs. $2040.5 \mathrm{pg} / \mathrm{mL} ; p=0.015$; Figure 5C) and pAkt expression level $<0.0036(n=19 ; 3307.8 \mathrm{pg} / \mathrm{mL}$ vs. $2122.0 \mathrm{pg} / \mathrm{mL}$; $p=0.020$; Figure 5D).
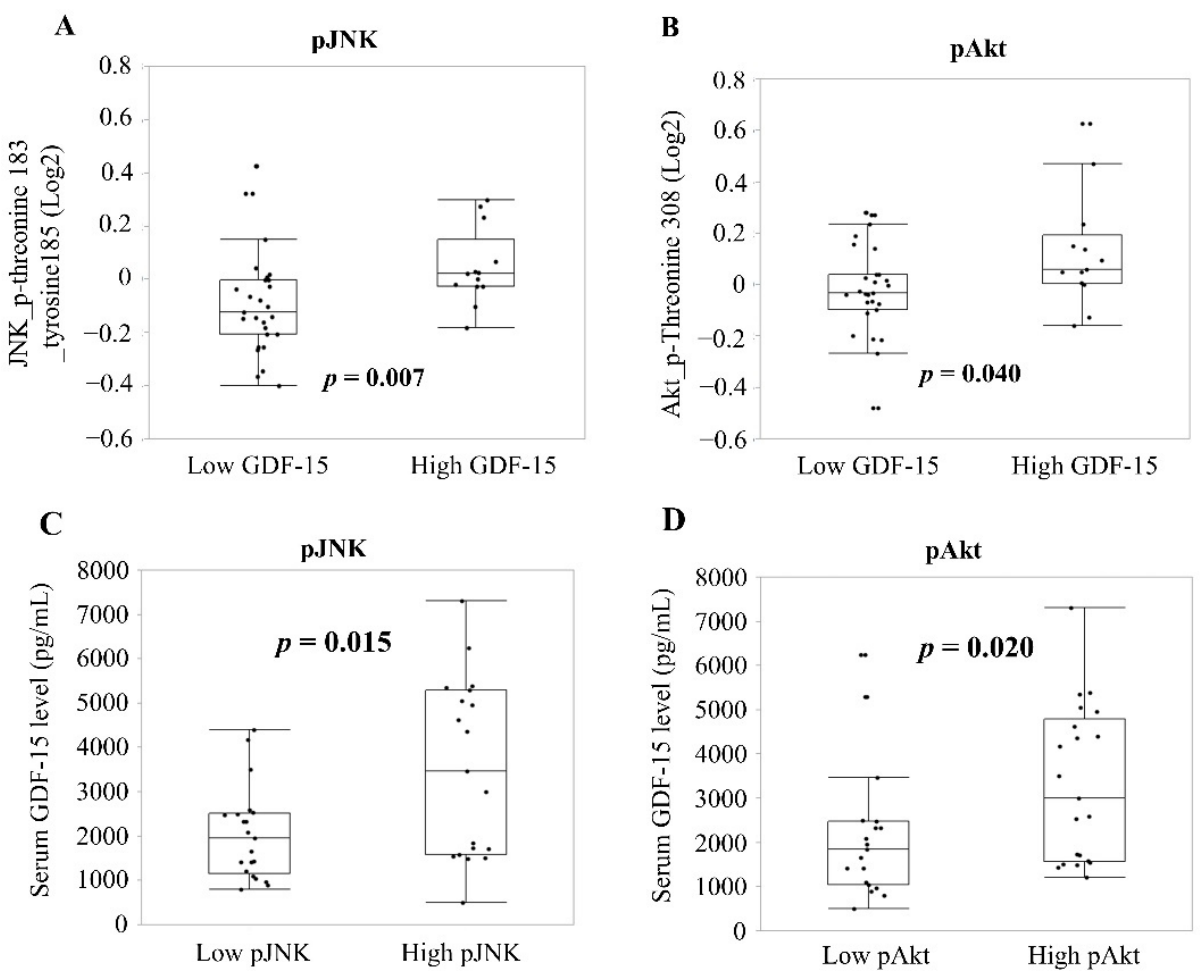

Figure 5. Tumor protein expression associated with serum GDF-15 levels by RPPA. Tumor protein expressions of (A) pJNK and (B) pAkt, represented as a binary logarithm, were compared among patients in the low- and high-GDF-15 groups. Serum GDF-15 levels, represented as logGDF-15, were compared among patients with high and low protein expressions of (C) pJNK and (D) pAkt in the tumor. Boxes indicate 5th and 95th percentiles. pJNK, phospho-JNK; pAkt, phospho-Akt.

\section{Discussion}

Mean circulating GDF-15 levels have been suggested to be higher in patients with pancreatic ductal adenocarcinoma, as $1731 \mathrm{pg} / \mathrm{mL}$ [23], 2428 [24], 7694.58 [1] and 2990.2 (this study), compared to patients with colorectal adenocarcinoma (CRC) $(1371.0 \mathrm{pg} / \mathrm{mL}$ [23] and $2030 \mathrm{pg} / \mathrm{mL}$ [25]), non-small-cell lung carcinoma (mean, $1258.0 \mathrm{pg} / \mathrm{mL}$ [23] and median, 828.8-2000 pg/mL [34,35]), and gastric adenocarcinoma (1154.0 pg/mL [23]). An atlas of the human transcriptome reported that GDF-15 mRNA expression was relatively low in pancreatic cancer compared to prostate, urothelial, renal, melanoma, and colorectal cancers [36]. The discrepancy between tumor mRNA expression and circulating level of GDF-15 may involve the ratio of patients with metastasis in each study population. A large proportion of CRC patients in a previous study [23] showed early-stage disease, although CRC patients with distant metastasis showed higher levels of serum GDF-15 (mean, $3531 \mathrm{pg} / \mathrm{mL}$ ) [25] and all APC patients in the present study showed liver metastasis. GDF-15 levels in various cancers should thus be assessed in concert with the ratio of metastasis in the study population. The diurnal pattern of serum GDF-15 levels needs to be clarified for evaluation of serum GDF-15. Circadian oscillation led to variations in serum GDF-15 levels near the midline estimating statistic of rhythm (MESOR) of about $\pm 10 \%$, with a MESOR of $381 \pm 15 \mathrm{pg} / \mathrm{mL}$ in healthy men [37]. In the present study, blood samples were obtained the morning after overnight fasting, and all APC patients showed liver 
metastasis. The effects of circadian oscillation and metastatic rate on circulating GDF-15 levels were considered to have been minimized in our study.

Our results showed that patients in the high-GDF-15 group experienced severe appetite loss compared with those in the low-GDF-15 group. In a previous study, median serum GDF-15 levels were higher in cancer patients with anorexia $(1224.1 \mathrm{pg} / \mathrm{mL})$ than in patients without anorexia $(812.4 \mathrm{pg} / \mathrm{mL})$ [34], where the cut-off value for anorexia was set at the lowest Functional Assessment of Anorexia/Cachexia Treatment (FAACT) score tertile, similar to the consensus definition of anorexia (FAACT $\leq 24)$ [38]. Our results showed that median MDASI scores in the high- and low-GDF-15 groups were 4 and 1 on a 0-10 scale, respectively. National Comprehensive Cancer Network (NCCN) guidelines for palliative care have proposed defining non-pain symptoms scoring $>4$ on the $0-10$ scale as severe [39]. In validation studies of MDASI, severe, moderate, and mild symptoms are defined as scores $\geq 7,5$ or 6 , and $1-4$, respectively [28,40]. The degrees of anorexia in highand low-GDF-15 groups corresponded to the upper and lower limits of mild anorexia, respectively. A prior report proposed the minimal clinical difference in numerical rating scale for anorexia as 1.5 points [41], and the median MDASI-J score in our study was 3 points higher in the high-GDF-15 group than in the low-GDF-15 group. On this basis, we concluded that patients in the high-GDF-15 group showed a clinically meaningful increase in the severity of anorexia compared with those in the low-GDF-15 group.

Our RPPA analysis revealed that expressions of pJNK and pAKT were significantly higher in the high-GDF-15 group than in the low-GDF-15 group. Tumor-associated stresses such as solid stress have been reported to induce phosphorylation of JNK and AKT [42-44]. Growth-induced solid stress in a tumor reflects an excessive tumor burden that compresses surrounding tissues $[45,46]$. APC patients with high serum GDF-15 levels also had high serum CA19-9 levels, suggesting high tumor burden [47]. Intriguingly, Akt and JNK have been shown to activate transcription of the GDF-15 gene [26,48] and to promote secretion of the GDF-15 protein $[5,49]$. We therefore speculate that increased solid stress due to a large tumor burden augments the expressions of pJNK and pAKT and also increases levels of circulating GDF-15. In addition, we observed that p-forkhead box-containing protein (FOX)O3a (serine 318_serine 321), p-tuberin (threonine_1462), and pElk-1 (serine 383) were highly expressed in the high-GDF-15 group compared to the low-GDF-15 group (Table S1). Activation of FOXO3a and tuberin was noted to promote tumor growth $[50,51]$, which was inhibited by Akt-mediated phosphorylation [52]. On the other hand, Elk1 was activated by JNK-mediated phosphorylation, leading to cell proliferation and oncogenesis [53]. These observations suggest that signaling pathways involving Akt and JNK play important roles in tumor growth in APC patients with high serum GDF-15 levels.

Evans' diagnostic criteria for cachexia include body weight loss, sarcopenia, systemic inflammation, appetite loss and fatigue, and are related to poor PS [54]. In our study, patients with high serum levels of GDF-15 showed severe appetite loss, systemic inflammation and poor PS, but not sarcopenia or body weight loss. We consider that an increase in tumor burden contributed to GDF-15-related anorexia via solid stress and was related to systemic inflammation and worsened PS prior to the onset of body weight loss and sarcopenia. A phase 1, first-in-humans, two-part, open-label clinical trial was recently started for CTL-002, a GDF-15 neutralizing antibody, recruiting subjects with advancedstage, relapsed, or refractory solid tumors (NCT04725474). The target patients will be evaluated for not only antitumor effect and safety, but also cachexia-related outcomes, since inhibition of GDF-15 biological activity has been shown to reverse body weight loss and restore muscle and fat tissue mass in several cachectic animal models [55]. This clinical trial of CTL-002 is expected to clarify the relationship between GDF-15 and cachexia.

The present study had a limitation that requires consideration when interpreting the results. This study had no validation cohort for the cut-off value of serum GDF-15 levels. Our cut-off value was able to discriminate the biological activity of JNL and AKT signaling in tumors as pathways producing GDF-15. In terms of biological activity, our cut-off value 
for serum GDF-15 was confirmed. Further studies to validate our cut-off for serum GDF-15 are warranted.

\section{Conclusions}

In conclusion, APC patients with high serum GDF-15 showed worsened performance status, anorexia and elevations of inflammation and tumor burden as signatures of cachexia, as well as activation of Akt and JNK in tumor GDF-15-producing pathways. This study indicated that circulating GDF-15 could be associated with cachectic symptoms in APC.

Supplementary Materials: The following are available online at https:/ /www.mdpi.com/article/10 .3390/ cancers13194842/s1, Table S1: Summary of results obtained from RPPA.

Author Contributions: Conceptualization, H.S., S.M., M.I., T.A., K.Y., H.Y., N.K., M.M., T.M. and A.O.; methodology, H.S. and S.M.; formal analysis, H.Y.; investigation, H.S.; resources, H.Y.; data curation, H.S.; writing — original draft preparation, H.S.; writing—review and editing, S.M., M.I., T.A., K.Y., H.Y., N.K., M.M., T.M. and A.O.; visualization, H.S.; supervision, S.M.; project administration, S.M. All authors have read and agreed to the published version of the manuscript.

Funding: This research received no external funding.

Institutional Review Board Statement: The study was conducted according to the guidelines of the Declaration of Helsinki, and approved by the Ethics Committee of National Cancer Center Hospital East (protocol code 2020-373 and 12 January 2021).

Informed Consent Statement: Informed consent was obtained from all subjects involved in the study.

Data Availability Statement: The datasets used and/or analyzed during the present study are available from the corresponding author on reasonable request.

Acknowledgments: The Functional Proteomics RPPA Core facility that generated the RPPA data in this study has been supported by Anderson Cancer Center Support Grant \#5 P30 CA016672-40. The authors thank Kayo Takei and Yuriko Sato of the National Cancer Center Hospital East for their secretarial support, and Mariko Yajima of the Exploratory Oncology Research \& Clinical Trial Center at the National Cancer Center for her support with the experiment.

Conflicts of Interest: H.Y. and N.K. are employees of Pfizer R\&D Japan G.K. The remaining authors have no conflicts of interest to declare.

\section{References}

1. Hogendorf, P.; Durczyński, A.; Skulimowski, A.; Kumor, A.; Poznańska, G.; Strzelczyk, J. Growth differentiation factor (GDF-15) concentration combined with Ca125 levels in serum is superior to commonly used cancer biomarkers in differentiation of pancreatic mass. Cancer Biomark. 2018, 21, 505-511. [CrossRef]

2. Traeger, L.; Ellermann, I.; Wiethoff, H.; Ihbe, J.; Gallitz, I.; Eveslage, M.; Moritz, R.; Herrmann, E.; Schrader, A.J.; Steinbicker, A.U. Serum hepcidin and GDF-15 levels as prognostic markers in urothelial carcinoma of the upper urinary tract and renal cell carcinoma. BMC Cancer 2019, 19, 74. [CrossRef]

3. Vocka, M.; Langer, D.; Fryba, V.; Petrtyl, J.; Hanus, T.; Kalousova, M.; Zima, T.; Petruzelka, L. Growth/differentiation factor 15 (GDF-15) as new potential serum marker in patients with metastatic colorectal cancer. Cancer Biomark. 2018, 21, 869-874. [CrossRef] [PubMed]

4. Li, J.; Veltri, R.W.; Yuan, Z.; Christudass, C.S.; Mandecki, W. Macrophage inhibitory cytokine 1 biomarker serum immunoassay in combination with PSA is a more specific diagnostic tool for detection of prostate cancer. PLoS ONE 2015, 10, e0122249. [CrossRef]

5. Roth, P.; Junker, M.; Tritschler, I.; Mittelbronn, M.; Dombrowski, Y.; Breit, S.N.; Tabatabai, G.; Wick, W.; Weller, M.; Wischhusen, J. GDF-15 contributes to proliferation and immune escape of malignant gliomas. Clin. Cancer Res. 2010, 16, 3851-3859. [CrossRef]

6. Wollert, K.C.; Kempf, T.; Wallentin, L. Growth differentiation factor 15 as a biomarker in cardiovascular disease. Clin. Chem. 2017, 63, 140-151. [CrossRef]

7. Yatsuga, S.; Fujita, Y.; Ishii, A.; Fukumoto, Y.; Arahata, H.; Kakuma, T.; Kojima, T.; Ito, M.; Tanaka, M.; Saiki, R.; et al. Growth differentiation factor 15 as a useful biomarker for mitochondrial disorders. Ann. Neurol. 2015, 78, 814-823. [CrossRef]

8. Zhao, J.; Li, M.; Chen, Y.; Zhang, S.; Ying, H.; Song, Z.; Lu, Y.; Li, X.; Xiong, X.; Jiang, J. Elevated serum growth differentiation factor 15 levels in hyperthyroid patients. Front. Endocrinol. 2019, 9, 793. [CrossRef]

9. Vila, G.; Riedl, M.; Anderwald, C.; Resl, M.; Handisurya, A.; Clodi, M.; Prager, G.; Ludvik, B.; Krebs, M.; Luger, A. The relationship between insulin resistance and the cardiovascular biomarker growth differentiation factor- 15 in obese patients. Clin. Chem. 2011, 57, 309-316. [CrossRef] 
10. Mullican, S.E.; Rangwala, S.M. Uniting GDF15 and GFRAL: Therapeutic opportunities in obesity and beyond. Trends Endocrinol. Metab. 2018, 29, 560-570. [CrossRef]

11. Patel, S.; Alvarez-Guaita, A.; Melvin, A.; Rimmington, D.; Dattilo, A.; Miedzybrodzka, E.L.; Cimino, I.; Maurin, A.C.; Roberts, G.P.; Meek, C.L.; et al. GDF15 provides an endocrine signal of nutritional stress in mice and humans. Cell Metab. 2019, 29, 707-718.e8. [CrossRef]

12. Ji, H.; Lu, H.W.; Li, Y.M.; Lu, L.; Wang, J.L.; Zhang, Y.F.; Shang, H. Twist promotes invasion and cisplatin resistance in pancreatic cancer cells through growth differentiation factor 15. Mol. Med. Rep. 2015, 12, 3841-3848. [CrossRef]

13. Johnen, H.; Lin, S.; Kuffner, T.; Brown, D.A.; Tsai, V.W.; Bauskin, A.R.; Wu, L.; Pankhurst, G.; Jiang, L.; Junankar, S.; et al. Tumor-induced anorexia and weight loss are mediated by the TGF-beta superfamily cytokine MIC-1. Nat. Med. 2007, 13, 1333-1340. [CrossRef]

14. Breen, D.M.; Kim, H.; Bennett, D.; Calle, R.A.; Collins, S.; Esquejo, R.M.; He, T.; Joaquim, S.; Joyce, A.; Lambert, M.; et al. GDF-15 neutralization alleviates platinum-based chemotherapy-induced emesis, anorexia, and weight loss in mice and nonhuman primates. Cell Metab. 2020, 32, 938-950.e6. [CrossRef]

15. Hendifar, A.E.; Chang, J.I.; Huang, B.Z.; Tuli, R.; Wu, B.U. Cachexia, and not obesity, prior to pancreatic cancer diagnosis worsens survival and is negated by chemotherapy. J. Gastrointest. Oncol. 2018, 9, 17-23. [CrossRef]

16. Fearon, K.; Strasser, F.; Anker, S.D.; Bosaeus, I.; Bruera, E.; Fainsinger, R.L.; Jatoi, A.; Loprinzi, C.; MacDonald, N.; Mantovani, G.; et al. Definition and classification of cancer cachexia: An international consensus. Lancet Oncol. 2011, 12, 489-495. [CrossRef]

17. Mitsunaga, S.; Kasamatsu, E.; Machii, K. Incidence and frequency of cancer cachexia during chemotherapy for advanced pancreatic ductal adenocarcinoma. Supportive Care Cancer 2020, 28, 5271-5279. [CrossRef]

18. Barber, M.D.; Ross, J.A.; Fearon, K.C. Changes in nutritional, functional, and inflammatory markers in advanced pancreatic cancer. Nutr. Cancer 1999, 35, 106-110. [CrossRef]

19. Gianotti, L.; Braga, M.; Radaelli, G.; Mariani, L.; Vignali, A.; Di Carlo, V. Lack of improvement of prognostic performance of weight loss when combined with other parameters. Nutrition 1995, 11, 12-16.

20. Mitsunaga, S.; Ikeda, M.; Shimizu, S.; Ohno, I.; Takahashi, H.; Okuyama, H.; Ueno, H.; Morizane, C.; Kondo, S.; Sakamoto, Y.; et al C-reactive protein level is an indicator of the aggressiveness of advanced pancreatic cancer. Pancreas 2016, 45, 110-116. [CrossRef]

21. Hromas, R.; Hufford, M.; Sutton, J.; Xu, D.; Li, Y.; Lu, L. PLAB, a novel placental bone morphogenetic protein. Biochim. Biophys. Acta 1997, 1354, 40-44. [CrossRef]

22. Yang, H.; Filipovic, Z.; Brown, D.; Breit, S.N.; Vassilev, L.T. Macrophage inhibitory cytokine-1: A novel biomarker for p53 pathway activation. Mol. Cancer Ther. 2003, 2, 1023-1029.

23. Wang, X.; Li, Y.; Tian, H.; Qi, J.; Li, M.; Fu, C.; Wu, F.; Wang, Y.; Cheng, D.; Zhao, W.; et al. Macrophage inhibitory cytokine 1 (MIC-1/GDF15) as a novel diagnostic serum biomarker in pancreatic ductal adenocarcinoma. BMC Cancer 2014, $14,578$. [CrossRef] [PubMed]

24. Koopmann, J.; Buckhaults, P.; Brown, D.A.; Zahurak, M.L.; Sato, N.; Fukushima, N.; Sokoll, L.J.; Chan, D.W.; Yeo, C.J.; Hruban, R.H.; et al. Serum macrophage inhibitory cytokine 1 as a marker of pancreatic and other periampullary cancers. Clin. Cancer Res. 2004, 10, 2386-2392. [CrossRef]

25. Xue, H.; Lü, B.; Zhang, J.; Wu, M.; Huang, Q.; Wu, Q.; Sheng, H.; Wu, D.; Hu, J.; Lai, M. Identification of serum biomarkers for colorectal cancer metastasis using a differential secretome approach. J. Proteome Res. 2010, 9, 545-555. [CrossRef]

26. Kalli, M.; Minia, A.; Pliaka, V.; Fotis, C.; Alexopoulos, L.G.; Stylianopoulos, T. Solid stress-induced migration is mediated by GDF15 through Akt pathway activation in pancreatic cancer cells. Sci. Rep. 2019, 9, 978. [CrossRef]

27. Nishikawa, H.; Shiraki, M.; Hiramatsu, A.; Moriya, K.; Hino, K.; Nishiguchi, S. Japan Society of Hepatology guidelines for sarcopenia in liver disease (1 st edition): Recommendation from the working group for creation of sarcopenia assessment criteria. Hepatol. Res. 2016, 46, 951-963. [CrossRef]

28. Okuyama, T.; Wang, X.S.; Akechi, T.; Mendoza, T.R.; Hosaka, T.; Cleeland, C.S.; Uchitomi, Y. Japanese version of the MD Anderson Symptom Inventory: A validation study. J. Pain Symptom Manag. 2003, 26, 1093-1104. [CrossRef] [PubMed]

29. Miura, T.; Mitsunaga, S.; Ikeda, M.; Ohno, I.; Takahashi, H.; Suzuki, H.; Irisawa, A.; Kuwata, T.; Ochiai, A. Characterization of low active ghrelin ratio in patients with advanced pancreatic cancer. Supportive Care Cancer 2018, 26, 3811-3817. [CrossRef]

30. Watanabe, K.; Mitsunaga, S.; Kojima, M.; Suzuki, H.; Irisawa, A.; Takahashi, H.; Sasaki, M.; Hashimoto, Y.; Imaoka, H.; Ohno, I.; et al. The "histological replacement growth pattern" represents aggressive invasive behavior in liver metastasis from pancreatic cancer. Cancer Med. 2020, 9, 3130-3141. [CrossRef] [PubMed]

31. Hennessy, B.T.; Lu, Y.; Gonzalez-Angulo, A.M.; Carey, M.S.; Myhre, S.; Ju, Z.; Davies, M.A.; Liu, W.; Coombes, K.; Meric-Bernstam, F.; et al. A technical assessment of the utility of reverse phase protein arrays for the study of the functional proteome in non-microdissected human breast cancers. Clin. Proteom. 2010, 6, 129-151. [CrossRef]

32. Mertins, P.; Yang, F.; Liu, T.; Mani, D.R.; Petyuk, V.A.; Gillette, M.A.; Clauser, K.R.; Qiao, J.W.; Gritsenko, M.A.; Moore, R.J.; et al. Ischemia in tumors induces early and sustained phosphorylation changes in stress kinase pathways but does not affect global protein levels. Mol. Cell. Proteom. 2014, 13, 1690-1704. [CrossRef] [PubMed]

33. Hu, J.; He, X.; Baggerly, K.A.; Coombes, K.R.; Hennessy, B.T.; Mills, G.B. Non-parametric quantification of protein lysate arrays. Bioinformatics 2007, 23, 1986-1994. [CrossRef] [PubMed] 
34. Molfino, A.; Amabile, M.I.; Imbimbo, G.; Rizzo, V.; Pediconi, F.; Catalano, C.; Emiliani, A.; Belli, R.; Ramaccini, C.; Parisi, C.; et al. Association between growth differentiation factor-15 (GDF-15) serum levels, anorexia and low muscle mass among cancer patients. Cancers 2020, 13, 99. [CrossRef] [PubMed]

35. Lerner, L.; Gyuris, J.; Nicoletti, R.; Gifford, J.; Krieger, B.; Jatoi, A. Growth differentiating factor-15 (GDF-15): A potential biomarker and therapeutic target for cancer-associated weight loss. Oncol. Lett. 2016, 12, 4219-4223. [CrossRef] [PubMed]

36. Uhlen, M.; Zhang, C.; Lee, S.; Sjöstedt, E.; Fagerberg, L.; Bidkhori, G.; Benfeitas, R.; Arif, M.; Liu, Z.; Edfors, F.; et al. A pathology atlas of the human cancer transcriptome. Science 2017, 357, eaan2507. [CrossRef] [PubMed]

37. Tsai, V.W.; Macia, L.; Feinle-Bisset, C.; Manandhar, R.; Astrup, A.; Raben, A.; Lorenzen, J.K.; Schmidt, P.T.; Wiklund, F.; Pedersen, N.L.; et al. Serum levels of human MIC-1/GDF15 vary in a diurnal pattern, do not display a profile suggestive of a satiety factor and are related to BMI. PLoS ONE 2015, 10, e0133362. [CrossRef] [PubMed]

38. Muscaritoli, M.; Anker, S.D.; Argilés, J.; Aversa, Z.; Bauer, J.M.; Biolo, G.; Boirie, Y.; Bosaeus, I.; Cederholm, T.; Costelli, P.; et al. Consensus definition of sarcopenia, cachexia and pre-cachexia: Joint document elaborated by Special Interest Groups (SIG) "cachexia-anorexia in chronic wasting diseases" and "nutrition in geriatrics". Clin. Nutr. 2010, 29, 154-159. [CrossRef] [PubMed]

39. National Comprehensive Cancer Network. Palliative Care. Version 2. 2021. Available online: https://www.nccn.org/ professionals/physician_gls/pdf/palliative.pdf (accessed on 12 February 2021).

40. Jones, D.; Vichaya, E.G.; Wang, X.S.; Williams, L.A.; Shah, N.D.; Thomas, S.K.; Johnson, V.E.; Champlin, R.E.; Cleeland, C.S.; Mendoza, T.R. Validation of the MD Anderson Symptom Inventory multiple myeloma module. J. Hematol. Oncol. $2013,6,13$. [CrossRef]

41. Bedard, G.; Zeng, L.; Zhang, L.; Lauzon, N.; Holden, L.; Tsao, M.; Danjoux, C.; Barnes, E.; Sahgal, A.; Poon, M.; et al. Minimal clinically important differences in the Edmonton symptom assessment system in patients with advanced cancer. J. Pain Symptom Manag. 2013, 46, 192-200. [CrossRef]

42. Chang, L.; Karin, M. Mammalian MAP kinase signalling cascades. Nature 2001, 410, 37-40. [CrossRef] [PubMed]

43. Hotamisligil, G.S. Endoplasmic reticulum stress and the inflammatory basis of metabolic disease. Cell 2010, 140, 900-917. [CrossRef] [PubMed]

44. Ye, L.; Zhao, D.; Xu, Y.; Lin, J.; Xu, J.; Wang, K.; Ye, Z.; Luo, Y.; Liu, S.; Yang, H. LncRNA-Gm9795 promotes inflammation in non-alcoholic steatohepatitis via NF-[Formula: See text]B/JNK pathway by endoplasmic reticulum stress. J. Transl. Med. 2021, 19, 101. [CrossRef]

45. Kalli, M.; Stylianopoulos, T. Defining the role of solid stress and matrix stiffness in cancer cell proliferation and metastasis. Front. Oncol. 2018, 8, 55. [CrossRef] [PubMed]

46. Nia, H.T.; Liu, H.; Seano, G.; Datta, M.; Jones, D.; Rahbari, N.; Incio, J.; Chauhan, V.P.; Jung, K.; Martin, J.D.; et al. Solid stress and elastic energy as measures of tumour mechanopathology. Nat. Biomed. Eng. 2016, 1, 0004. [CrossRef] [PubMed]

47. Marchegiani, G.; Andrianello, S.; Malleo, G.; De Gregorio, L.; Scarpa, A.; Mino-Kenudson, M.; Maggino, L.; Ferrone, C.R.; Lillemoe, K.D.; Bassi, C.; et al. Does size matter in pancreatic cancer? Reappraisal of tumour dimension as a predictor of outcome beyond the TNM. Ann. Surg. 2017, 266, 142-148. [CrossRef]

48. Appierto, V.; Tiberio, P.; Villani, M.G.; Cavadini, E.; Formelli, F. PLAB induction in fenretinide-induced apoptosis of ovarian cancer cells occurs via a ROS-dependent mechanism involving ER stress and JNK activation. Carcinogenesis 2009, 30, 824-831. [CrossRef]

49. Welsh, J.B.; Sapinoso, L.M.; Kern, S.G.; Brown, D.A.; Liu, T.; Bauskin, A.R.; Ward, R.L.; Hawkins, N.J.; Quinn, D.I.; Russell, P.J.; et al. Large-scale delineation of secreted protein biomarkers overexpressed in cancer tissue and serum. Proc. Natl. Acad. Sci. USA 2003, 100, 3410-3415. [CrossRef]

50. Hu, M.C.; Lee, D.F.; Xia, W.; Golfman, L.S.; Ou-Yang, F.; Yang, J.Y.; Zou, Y.; Bao, S.; Hanada, N.; Saso, H.; et al. IkappaB kinase promotes tumorigenesis through inhibition of forkhead FOXO3a. Cell 2004, 117, 225-237. [CrossRef]

51. Tee, A.R.; Fingar, D.C.; Manning, B.D.; Kwiatkowski, D.J.; Cantley, L.C.; Blenis, J. Tuberous sclerosis complex-1 and -2 gene products function together to inhibit mammalian target of rapamycin (mTOR)-mediated downstream signaling. Proc. Natl. Acad. Sci. USA 2002, 99, 13571-13576. [CrossRef]

52. Plas, D.R.; Thompson, C.B. Akt activation promotes degradation of tuberin and FOXO3a via the proteasome. J. Biol. Chem. 2003, 278, 12361-12366. [CrossRef]

53. Zhong, S.; Fromm, J.; Johnson, D.L. TBP is differentially regulated by c-Jun N-terminal kinase 1 (JNK1) and JNK2 through Elk-1, controlling c-Jun expression and cell proliferation. Mol. Cell. Biol. 2007, 27, 54-64. [CrossRef] [PubMed]

54. Evans, W.J.; Morley, J.E.; Argilés, J.; Bales, C.; Baracos, V.; Guttridge, D.; Jatoi, A.; Kalantar-Zadeh, K.; Lochs, H.; Mantovani, G.; et al. Cachexia: A new definition. Clin. Nutr. 2008, 27, 793-799. [CrossRef] [PubMed]

55. Lerner, L.; Tao, J.; Liu, Q.; Nicoletti, R.; Feng, B.; Krieger, B.; Mazsa, E.; Siddiquee, Z.; Wang, R.; Huang, L.; et al. MAP3K11/GDF15 axis is a critical driver of cancer cachexia. J. Cachexia Sarcopenia Muscle 2016, 7, 467-482. [CrossRef] 